\title{
"Benefits of the pedicled osteoplastic flap as a surgical approach of mastoidectomy in cochlear implant surgery"
}

\author{
Paula Tardim Lopes ${ }^{1,7}\left[\right.$ [D $\cdot$ Ricardo Ferreira Bento ${ }^{2,7}$. Eloisa Maria Mello Santiago Gebrim ${ }^{3,7}$. \\ Roberto Miquelino de Oliveira Beck ${ }^{4,7}$. Renata Mota Memede Carvallo ${ }^{5,7}$. Seisse Gabriela Gandolfi Sanches ${ }^{6,7}$. \\ Juan Carlos Cisneros Lesser ${ }^{7}$
}

Received: 17 February 2021 / Accepted: 25 May 2021 / Published online: 10 June 2021

(c) The Author(s), under exclusive licence to Springer-Verlag GmbH Germany, part of Springer Nature 2021

\begin{abstract}
Objective To evaluate the esthetic and functional results of an osteoplastic flap for mastoid cavity closure in cochlear implant surgery.

Study design Double-blind, prospective, randomized clinical trial. Setting: tertiary referral center.

Intervention(s) On hundred and twenty-six patients were randomized in 2 groups for cochlear implant surgery. Cases ( $n$ : 63) underwent simple mastoidectomy using an anteriorly pedicled osteoplastic flap for mastoid closure. In controls ( $n$ : 63), a traditional periosteal flap was used. Evaluation with the POSAS questionnaire was performed 1 year after surgery to assess surgical wound esthetics. Sixteen patients from each group had postoperative CT-scans and wideband tympanometry to assess mastoid aeration and middle ear absorbance. Gender and time after surgery were correlated.

Main outcome measure(s) Evaluation of the quality of the surgical wound with the application of a questionnaire validated in the medical literature and translated into Portuguese language called POSAS, considering the perception of the blinded patient and doctor regarding the surgical technique proceeded. A lower POSAS score suggests better esthetics of the surgical wound. Secondary outcomes are volumetric measurement of aeration inside mastoid cavity using 3D computer tomography exam, which aims to analyze the influence of fibrocicatricial retraction in the surgical wound into the mastoid and the interference of its aeration volume in the absorption of sound in the middle ear, using the wideband tympanometry exam.

Results The POSAS questionnaire in the Case group showed a lower level of local pain and itchiness, a skin color and thickness more similar to the surrounding skin and less irregularity and stiffness, with no influence from time after surgery and gender compared to the Control group. The median tomographic volume was $6.37 \mathrm{cc}$ in the cases and $4.60 \mathrm{cc}$ in controls. Wideband tympanometry showed general smaller sound absorbance in the Case group results, specially, at $1000 \mathrm{~Hz}$ frequency. No intraoperative or postoperative complications were observed with the osteoplastic flap.

Conclusions This technique is an effective and safe alternative to alleviate common problems of mastoid surgery for cochlear implantation. In addition to esthetic benefits, it has less interference in middle ear physiology of sound absorbance and less fibrous tissue into the mastoid cavity during the follow-up of more than 1 year.
\end{abstract}

Keywords Surgical flap $\cdot$ Mastoidectomy $\cdot$ Cochlear implant $\cdot$ Wound healing $\cdot$ Esthetics $\cdot$ Acoustic impedance tests

\section{Introduction}

The evolution of implantable hearing aids, such as cochlear implants, implies the evaluation and improvement of mastoidectomy surgical techniques in mastoids without inflammatory disease, with the consideration of producing

Paula Tardim Lopes

paulatardimlopes@gmail.com

Extended author information available on the last page of the article fewer alterations to the local physiology and greater esthetic satisfaction [1,2].

Mastoid surgery retroauricular incisions and mastoid cavities produce retroauricular skin depression and fibrosis over time in a great number of patients. In addition to this esthetic inconvenience, surgical wounds with more retraction and deformity after cochlear implant surgery may generate other problems over time such as local discomfort in the retroauricular region when using the retroauricular speech processor and accessories such as caps glasses and 
masks, accumulation of skin shedding and difficulty for dirt removal. These are complaints reported in the office, which most of the times are disregarded by surgeons in their practice. Improving the quality of surgical healing, to obtain a retroauricular skin more similar to the original, may alleviate these complaints (Fig. 1).

A functional problem can also be generated in the middle ear because of the depression in the retroauricular region, the loss of mastoid air cells and their respiratory epithelium and the fibrosis which enters the mastoid cavity, producing alterations in normal middle ear physiology [3-5]. These alterations may increase the risk for developing chronic otitis media, cholesteatoma or recurrent acute otitis media, with a greater risk of prosthesis infection leading to explantation or even a greater risk for meningitis [6].

The mastoid cavity works as an air reservoir that helps in the effective conduction of sound, working as a resonance box and it also sustains the middle ear pressure during pressure fluctuations [7-9]. Mastoid cavities that sustain larger volumes can be a protective factor against the development of pathological diseases in the middle ear such as infection, which is especially important for patients with implantable hearing devices [10-12].

A new autologous, anteriorly pedicled osteoplastic flap, composed of bone, muscle and periosteum, for the closure of the mastoid cavity after cochlear implant surgery is described in this study (Fig. 2).

This flap is readily available during surgery, more economically viable than heterologous grafts, since it has no cost or chance of foreign body reaction. This study aims to evaluate the functional and esthetic results using the newly proposed osteoplastic flap for mastoid cavity closure after cochlear implantation, compared with the traditional closure with a periosteal flap by applying a questionnaire of esthetic satisfaction with the surgical wound called POSAS [13], as well as the middle ear air volume observed by computed tomography and middle ear sound absorbance by wideband tympanometry to measurements of middle ear compliance [14]. We also evaluate surgical complications of the proposed technique during the intraoperative and postoperative periods.

\section{Materials and methods}

This study is a double-blind (participants and physicians who applied the questionnaire, physicians who proceeded the wideband tympanometry), parallel, prospective, randomized clinical trial. The method used to generate the random allocation sequence was a patient draw using letters of
Fig. 1 Retroauricular aspect of mastoidectomy scar (A). Using traditional periosteal flap pro closing. B Using the proposed osteoplastic flap

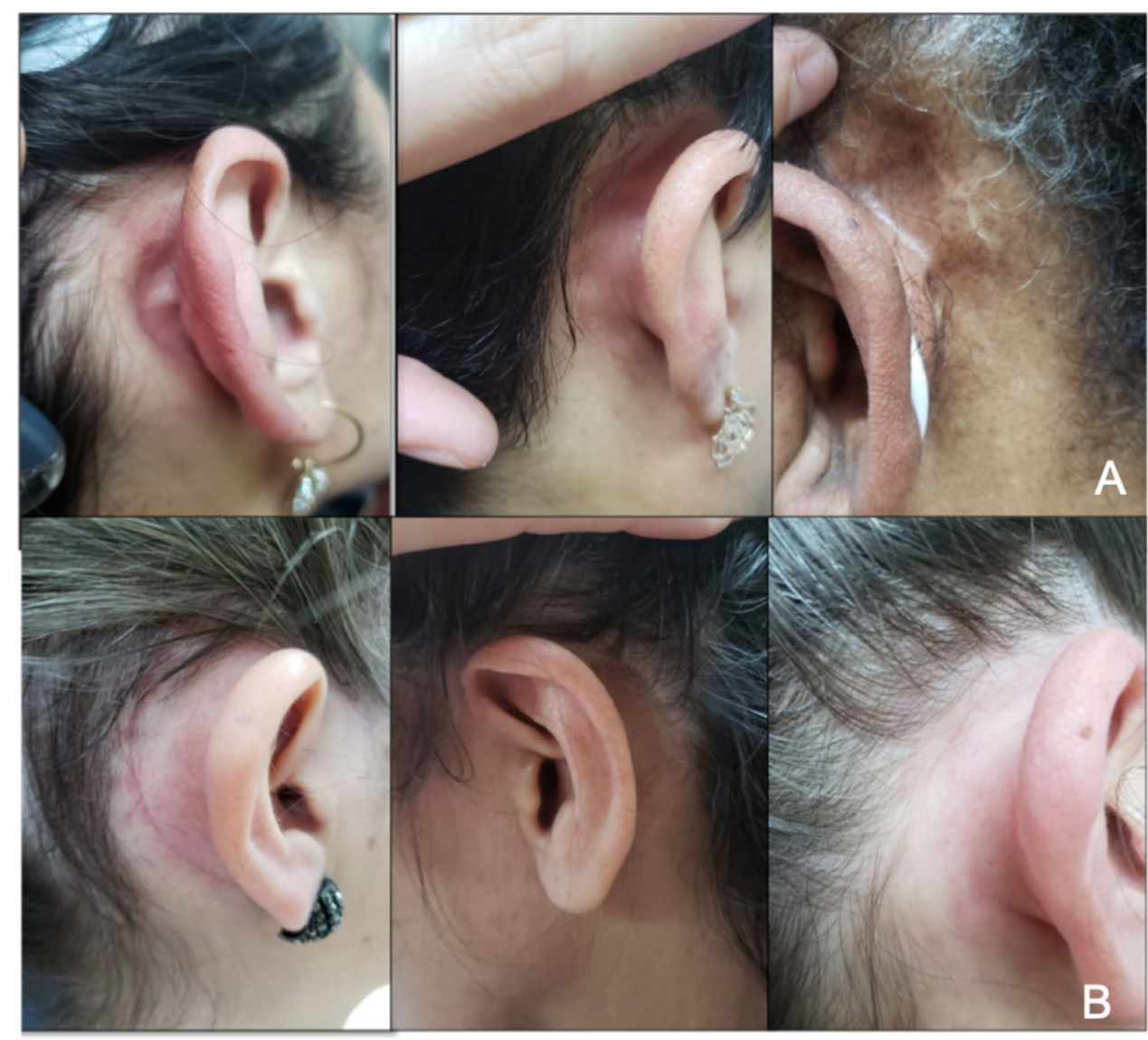




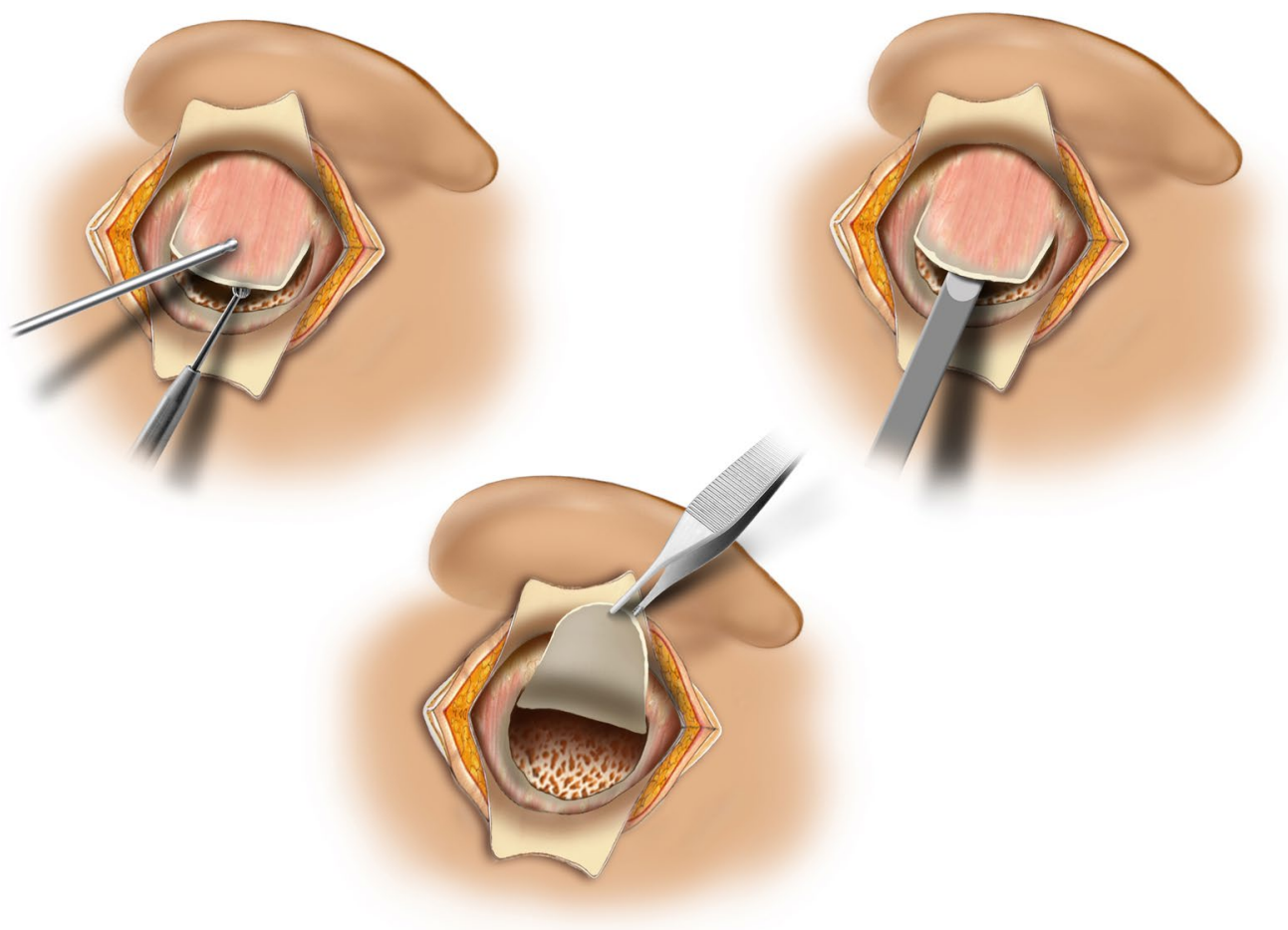

Fig. 2 Osteoplastic flap confection

the alphabet including 126 patients from a tertiary referral center at the time of undergoing cochlear implant surgery. The website www.randomized.com generated the random allocation sequence for all participants into 2 groups of interventions with 63 patients each one, Case and Control groups.

They were followed during 1-5 years after the surgical procedure. Convenience sample size was obtained for a $95 \%$ confidence interval, considering the evaluation of the primary objective (esthetic satisfaction). The participants were designated to enroll in the normal queue to be operated according to criteria for cochlear implant surgical indication, that follows the guidelines of the Brazilian healthcare system.

The Case group (C) (n=63), underwent simple mastoidectomy for cochlear implant surgery, using the newly proposed anteriorly pedicled osteoplastic flap and the Control group $(\mathrm{Cc})(n=63)$, had a traditional surgical opening and closing technique with a simple periosteal flap. All patients were evaluated more than 1 year after surgery, regarding the esthetic parameter of the surgical wound with the application of a questionnaire (POSAS), and the influence of time variation for applying this questionnaire was also studied considering the results obtained.

The POSAS questionnaire is composed of two parts: the patient's esthetic satisfaction and the examiner's perception of the quality of the surgical wound. Both patients and examiners were blinded to the surgical technique employed.
The pandemic of covid 19 led to the closure of the hospital in which this study was enrolled, and than designed to provide exclusive treatment to patients with coronavirus.

The pandemic caused a main change in the method, such as eligibility criteria to proceed CT-scan exam and wideband tympanometry in all operated patients. For this reason, from each group, only 16 patients were selected using the website for randomization to assess mastoid air volume through a 3D-CT-scan, analyzed by radiologists from the same hospital. Images were evaluated using the IntelliSpace PACS DCX 3.1, Philips Healthcare software. Axial images were reconstructed for multiplanar three-dimensional volumetric assessment (3D-MPVR) and measurements of temporal bone aeration were obtained with intervals of densities ranging between $-1025 \mathrm{UH}$ and $25 \mathrm{UH}$. This range of attenuation values corresponds to the aerated spaces, with the removal of bone and soft tissue attenuation by Koç $\mathrm{A}$ et al. [15].

Those 2 subgroups of 16 patients each were also randomized selected to be submitted to Wideband Tympanometry (WBT) to measure sound absorbance in the middle ear [16]. But from the Case group, only 14 patients and, from Control group, only 12 patients did this exam.

There was a loss of two patients in the Case group and four patients in the Control group because, one patient from the Case group had tympanic membrane perforation and one patient did not attend the examination. In the Control group, one patient had perforation of the tympanic membrane, one 
had otitis in the ear that would be analyzed, and other two were excluded due to equipment failure (Fig. 3).

In addition, the correlation between the degree of mastoid aeration and sound absorbance in both subgroups was tested. In addition, we studied if gender and time after surgery had an influence on the results.

The project was approved by the research and ethics committee of the University of São Paulo Hospital das Clínicas with approval number of clinical trial 2.670.119.

\section{Inclusion criteria}

Patients 18 years or older, with normal mastoid and middle ear anatomy assessed by computed tomography exams, who undergo cochlear implant surgery at University of São Paulo Hospital das Clínicas.

\section{Exclusion criteria}

- Acute or chronic otitis media at the time of surgery, computed tomography exam or wideband tympanometry;

- Patients with the following tomographic changes in the preoperative period:

- sigmoid sinus displaced laterally or posteriorly towards the cortical of the mastoid and prominent;

- malformation of the inner and/or middle ear;

- Deafness due to cranial trauma or temporal bone fracture;

- Diagnosis of chronic serous otitis media with an otoscopy showing retrotympanic secretion in the preoperative or intraoperative period.

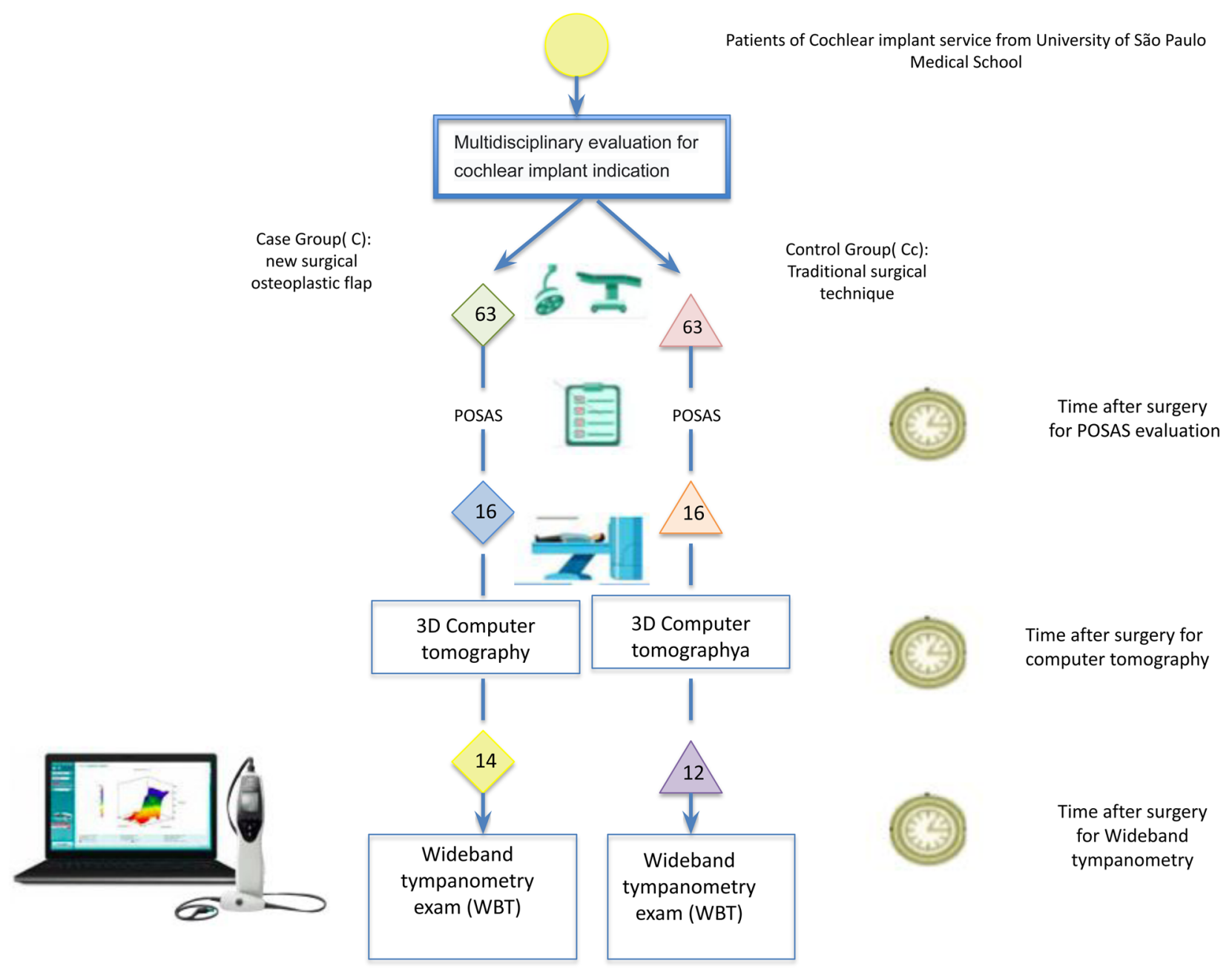

Fig. 3 Flow diagram of the clinical trial 


\section{Surgical technique}

As described by Bento et al. [17], a " $\mathrm{C}$ " incision is performed $2 \mathrm{~cm}$ behind the postauricular region. An anteriorly pedicled muscular flap with a " $U$ " shape is performed, maintaining its union to the cartilaginous external auditory canal and mastoid bone. A small periosteal elevator separates the periosteum from the entire incision to expose the cortical mastoid bone to drill in the same "U" shape. Using a $2.5 \mathrm{~mm}$ drill bit, the cortical bone is opened in the entire perimeter of the "U" at a depth of approximately $3 \mathrm{~mm}$. Then, with the drill acting at an angle of approximately 20 degrees in relation to the cortical, an osteoplastic flap approximately $3 \mathrm{~mm}$ thick all around is created. A $10 \mathrm{~mm}$ chisel is introduced through the superficial cells of the mastoid and, using a surgical hammer, it is elevated anteriorly, until it gets close to the external auditory canal. When the entire extension of the osteoperiosteal flap is detached from the cortical bone, leaving the periosteum attached to it, the flap is elevated, allowing to proceed with the mastoidectomy, as it would be performed in a conventional technique for cochlear implant surgery.

At the end of surgery, the flap is repositioned over the cavity and the periosteum borders are sutured with the corresponding periosteum. The suture is made in two planes involving the muscle and the subcutaneous with vicryl 3.0 monofilament and the skin with nylon 4.0 thread (Fig. 4).

\section{Results}

Descriptive analyzes for quantitative data were incorporated into the means accompanied by standard deviations (+SD). Quantitative data without normal distribution were expressed using medians and interquartile IQ intervals $(25-75 \%)$. The assumption of normal distribution of variables was assessed using the Shapiro-Wilk test. Categorical variables were expressed through their frequencies and percentages.

For quantitative variables, Student's $t$ test or Mann-Whitney test was used when the variable did not present a normal distribution. For the variable absorbance, two factors were

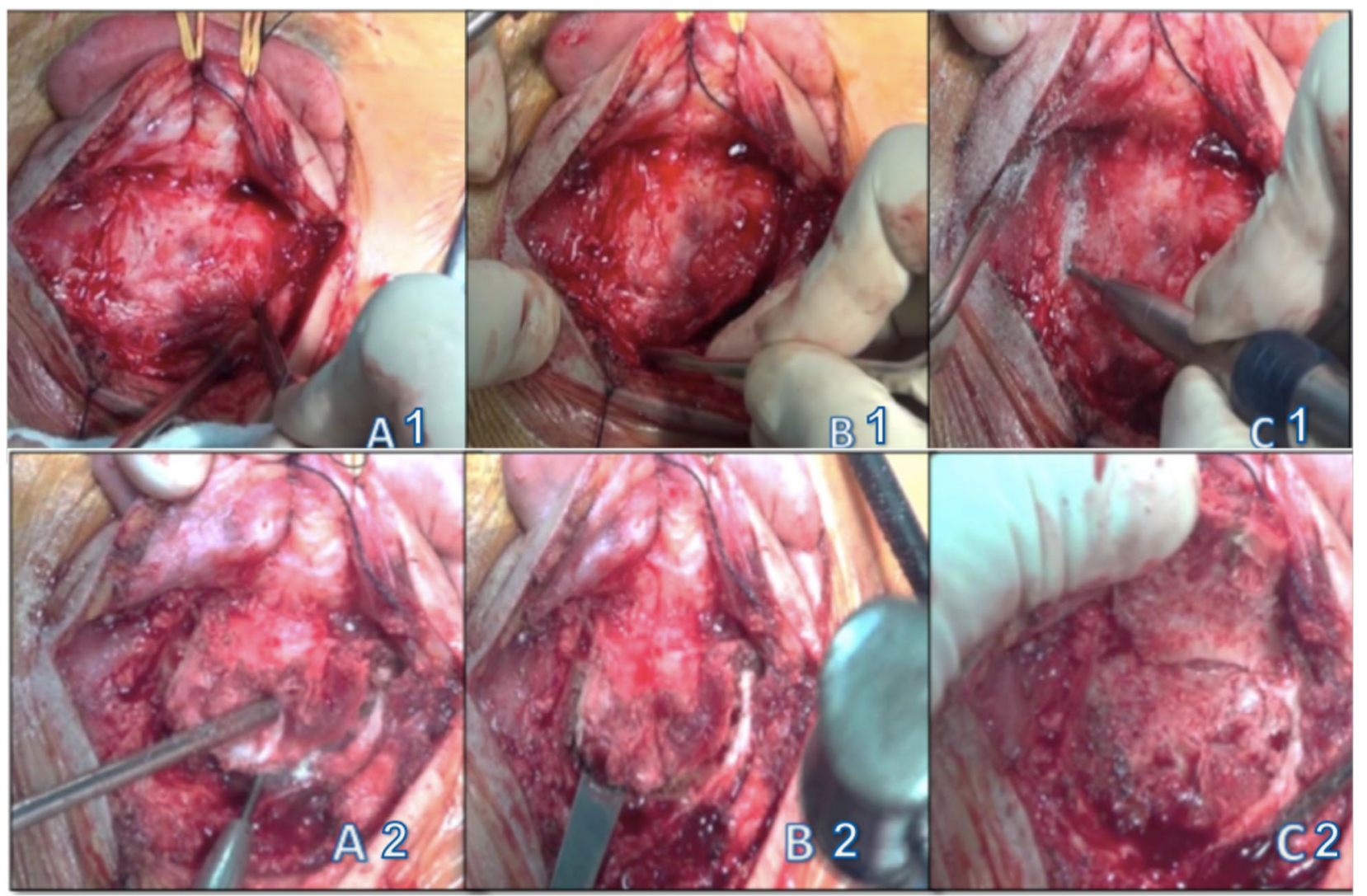

Fig. 4 Intraoperative steps of making the proposed osteoplastic flap: U-shaped incision in the mastoid cortex (A1), detachment of the periosteum at the incision site (B1) and boring of the mastoid cortex at the "U shaped" incision $(\mathbf{C} 1)$. Boring at an angle of approximately
20 degrees with the U-shaped mastoid cortex (A2). Use of chisel and hammer to elevate the bone, periosteal and muscle flap (B2). Anterior positioning of the flap (C3) 
analyzed (Group and Frequency), double-factor ANOVA of repeated measures for a single factor (Frequency) was used. Categorical variables were analyzed using the Chisquare test or Fisher's exact test when necessary. To assess the association between variables, Spearman's correlation test was used. All comparison data between the Case (C) and Control (Cc) groups at the different times studied were analyzed using the IBM SPSS $®$ Statistics V21.0 for Windows software. The level of significance used was $5 \%(\alpha=0.05)$.

According to gender distribution, we had 21 male patients (33.3\%) in the $\mathrm{C}$ group and 30 (47.6\%) in the Cc group and 42 female patients (66.7\%) in the $\mathrm{C}$ group and 33 (52.4\%) in the Cc group. We had a median age of 51 years for the $\mathrm{C}$ group and 42 years for the $\mathrm{Cc}$ group. There were no statistically significant differences between the ages and genders of the studied groups (Table 1).

Time after surgery in which the questionnaires POSAS was applied had a median of 788 days after surgery in the $\mathrm{C}$ group and 857 days in the Cc group, with no statistical difference between the groups, POSAS results correlated to time after surgery presented with worse scores by the patient and the examiner in both groups. Responses were especially worse for the Control group, with a statistically significant difference in this parameter, observing a negative Spearman correlation $\mathrm{R}=0,283(p=0.024)$ in the $\mathrm{Cc}$ group between POSAS result and time after surgery, in comparison to an $\mathrm{R}=0,049 ; p=0.705$ in the $\mathrm{C}$ group).

The table below (Table 2) shows the variables analyzed POSAS questionnaires (vascularization, pigmentation, thickness, prominence, flexibility, irregularity and general opinion). A value of 1 is considered to be the best score (best appearance and the same as original skin surround), and values from 2 to 10 are considered to be different from normal skin, and the higher the value, the worse is the result. As result, all variables were better for the $\mathrm{C}$ group according to both, patients and examiners, obtaining statistically significant differences.

Secondary outcomes measures are mastoid volume aeration measured using CT-scan and result of sound absorbance using wideband tympanometry. The mastoid aeration volume was better in the $\mathrm{C}$ group (median volume in $\mathrm{C}$ group $6.37 \mathrm{cc}$ vs $4.60 \mathrm{cc}$ in Cc group) (Fig. 5).

Patients from $\mathrm{Cc}$ group had the CT exam performed later on average than in the $\mathrm{C}$ group (average time: 407 days for the $\mathrm{C}$ group vs 1402 days in Cc group). In spite of the difference in time to perform the CT-scan after surgery between the two groups, the $\mathrm{R}$ value was low and with no statistical significance, and results were better in the $\mathrm{C}$ group which means that after the follow-up minimum of 1 year from surgery, time does not interfere to improve mastoid aeration and results are attributed solely from the difference in surgical techniques.

Concerning the sound absorbance obtained with the wideband tympanometry test, the values were higher in the C group (mean: 0.426, SD 0.01) compared to the Cc group (mean: 0.323 and SD 0.029). There were statistically significant differences between the results of the two groups in 250,500 and $1000 \mathrm{~Hz}$ frequencies values in favor of the $\mathrm{C}$ group, and a tendency to have a better sound absorbance in higher frequencies, but with no statistically significant difference (Fig. 6).

We observed a positive and significant correlation between the volume of the mastoid and the absorbance at the frequency of $2000 \mathrm{~Hz}$ in the Case group (C), showing that the greater the air volume of the mastoid, the greater the sound absorbance at $2000 \mathrm{~Hz}(\mathrm{R}=0.604$ and $p=0.038)$.

Factors related to gender and age did not affect the result of the evaluation of the surgical wound.

At last, we report no intraoperative and postoperative complications from the proposed surgical osteoplastic flap in the studied patients.

\section{Discussion}

Otitis media is a complication more frequent in implanted patients ( $42 \%$ of children with comorbidities and $6.6 \%$ without comorbidity) [18] and also, middle ear infections were
Table 1 General analysis of population characteristics

\begin{tabular}{lll}
\hline & Case & Control \\
\hline Gender-n (\%) & & \\
Male: $\mathrm{n}(\%)$ & $21(33.3 \%)$ & $30(47.6 \%)$ \\
Female: $\mathrm{n}(\%)$ & $42(66.7 \%)$ & $33(52.4 \%)$ \\
Age (years): median (IQ) & $51(36.5-57)$ & $42(27.5-54)$ \\
Sum of patients POSAS values: median (IQ) & $6(6-6)$ & $8(7-12)$ \\
Sum of observer POSAS values: median (IQ) & $7(7-10,5)$ & $11(7-16)$ \\
Time after surgery(days): median (IQ) & $788(48.5-106.5)$ & $857(482.5-151.5)$ \\
Tomographic volume aeration: median (IQ) & $6.37(5.19-7.59)$ & $4.60(3.87-6.31)$ \\
Time after surgery for tomography (days): median (IQ) & $407(385-510)$ & $1402(573-1496)$ \\
Time after surgery for WBT (days) & $1469.2 \pm 511.9$ & $928.9 \pm 371.7$ \\
\hline
\end{tabular}


Table 2 Percentage evaluation of each POSAS item in the Case and Control groups for patient and observer evaluation

POSAS observer

\begin{tabular}{|c|c|c|c|}
\hline \multirow[t]{2}{*}{ Variables } & \multicolumn{2}{|c|}{ Score POSAS } & \multirow[t]{2}{*}{$p$} \\
\hline & $\leq 1$ & $>1$ & \\
\hline \multicolumn{4}{|c|}{ P1 Vascularization } \\
\hline Case & $51(81 \%)$ & $12(19 \%)$ & \multirow[t]{2}{*}{0.818} \\
\hline Control & $52(82.5 \%)$ & $11(17.5 \%)$ & \\
\hline \multicolumn{4}{|c|}{ P2 Pigmentation } \\
\hline Case & $19(30.2 \%)$ & $44(6.8 \%)$ & \multirow[t]{2}{*}{0.148} \\
\hline Control & $12(19 \%)$ & $51(81 \%)$ & \\
\hline \multicolumn{4}{|c|}{ P3 Thickness } \\
\hline Case & $50(79.4 \%)$ & $13(20.6 \%)$ & \multirow[t]{2}{*}{$<0.001$} \\
\hline Control & $26(4.3 \%)$ & $37(58.7 \%)$ & \\
\hline \multicolumn{4}{|l|}{ P4 Relief } \\
\hline Case & $45(71.4 \%)$ & $18(28.6 \%)$ & \multirow[t]{2}{*}{$<0.001$} \\
\hline Control & $23(36.5 \%)$ & $40(63.5 \%)$ & \\
\hline \multicolumn{4}{|c|}{ P5 Pliability } \\
\hline Case & $45(71.4 \%)$ & $18(28.6 \%)$ & \multirow[t]{2}{*}{$<0.001$} \\
\hline Control & $23(36.5 \%)$ & $40(63.5 \%)$ & \\
\hline \multicolumn{4}{|c|}{ P6 Roughness } \\
\hline Case & $11(17.5 \%)$ & $52(82.5 \%)$ & \multirow[t]{2}{*}{0.016} \\
\hline Control & $23(36.5 \%)$ & $40(63.5 \%)$ & \\
\hline \multicolumn{4}{|c|}{ P7 General opinion } \\
\hline Case & $57(90.5 \%)$ & $6(9.5 \%)$ & \multirow[t]{2}{*}{$<0.001$} \\
\hline Control & $10(15.9 \%)$ & $53(84.1 \%)$ & \\
\hline \multicolumn{4}{|c|}{ POSAS patients } \\
\hline \multirow[t]{2}{*}{ Variables } & \multicolumn{2}{|c|}{ Score POSAS } & \multirow[t]{2}{*}{$p$} \\
\hline & $\leq 1$ & $>1$ & \\
\hline \multicolumn{4}{|l|}{ P1 Pain } \\
\hline Case & $55(87.3 \%)$ & $8(12.7 \%)$ & \multirow[t]{2}{*}{$<0.001$} \\
\hline Control & $10(15.9 \%)$ & $53(84.1 \%)$ & \\
\hline \multicolumn{4}{|l|}{ P2 Itch } \\
\hline Case & $54(85.7 \%)$ & $9(14.3 \%)$ & 0.032 \\
\hline Control & $44(69.8 \%)$ & $19(30.2 \%)$ & \\
\hline P3 Color & & & \\
\hline Case & $59(93.7 \%)$ & $4(6.3 \%)$ & 0.003 \\
\hline Control & $47(74.6 \%)$ & $16(25.4 \%)$ & \\
\hline P4 Skin st & & & \\
\hline Case & $57(90.5 \%)$ & $6(9.5 \%)$ & 0.011 \\
\hline Control & $46(73 \%)$ & $17(27 \%)$ & \\
\hline P5 Thickn & & & \\
\hline Case & $59(93.7 \%)$ & $4(6.3 \%)$ & 0.001 \\
\hline Control & $44(69.8 \%)$ & $19(30.2 \%)$ & \\
\hline P6 Irregul & & & \\
\hline Case & $59(93.7 \%)$ & $4(6.3 \%)$ & 0.001 \\
\hline Control & $44(69.8 \%)$ & $19(30.2 \%)$ & \\
\hline P7 Genera & & & \\
\hline Case & $51(81 \%)$ & $12(19 \%)$ & 0.002 \\
\hline Control & $35(55.6 \%)$ & $28(44.4 \%)$ & \\
\hline
\end{tabular}




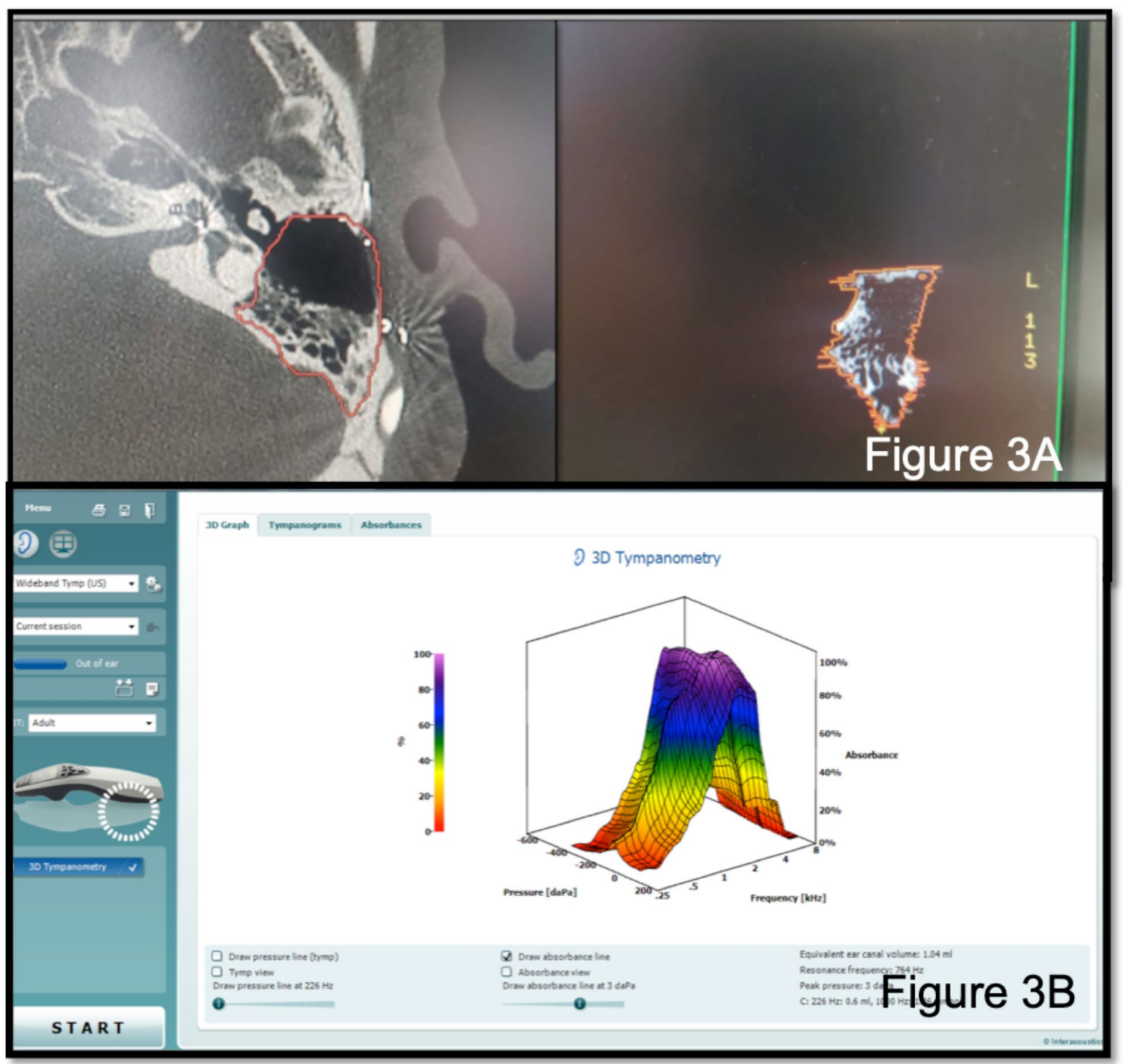

Fig. 5 A Aspect of aeration of a mastoid cavity in axial tomographic section. B Three-dimensional absorbance curve at all frequencies applied in the wideband tympanometry test

diagnosed in $37 \%$ of the implanted ears [19] with a risk 30 times higher of meningitis the first 2 years [20]. These are important reasons to be considered for improving the surgical technique and expand it to other surgeries using mastoidectomies approaches without inflammatory disease.

The novelty of this research is that it shows a statistically significant difference in the scar esthetics results using the two different mastoidectomy open and closure techniques. This strengthens the need to address this issue (scar aspect) by the professional.

In addition, patients submitted to the $\mathrm{C}$ group (osteoplastic flap technique proposed) had better mastoid aeration volumes when compared to patients in which simple closure with periosteum was performed, promoting less fibrocicatricial tissue formation inside the mastoid cavity during the time.

Sound absorbance in the middle ear was higher in the group with the proposed flap technique, strengthening the argument of some authors, who state that a normal mastoid mucosa is responsible for better gas exchange and better maintenance of the aeration in this cavitary system [21].

Variations in mastoid volume are relevant to the physiology of the middle ear, as observed when sound absorbance is studied in relation to mastoid aeration. 
Timpanometry

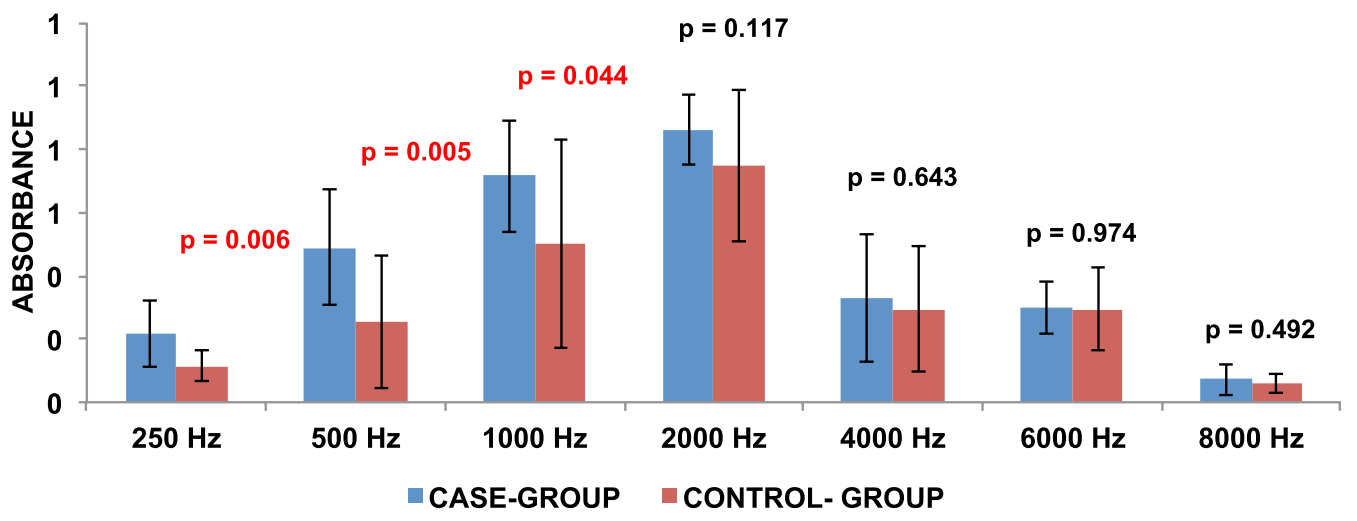

Fig. 6 Comparative graph of the absorbance medians for each specific frequency between Case and Control groups

We know from previous works regarding absorbance results, that the conductive alterations generate less sound absorbance, due to the greater rigidity of the system [22-25]. Even though, the values observed were within the normal range in high frequencies, the $\mathrm{C}$ group has the absorbance values closer to the expected normality. This shows that the surgical technique proposed causes less interference in sound absorption of important speech frequencies and middle ear physiology.

Limitation of this study were the cost and availability of imitanciometer Tintan used to measure the absorbance and difficulty to reproduce this study in other hospitals that are not research centers, beyond the limited number of patients studied with this wideband tympanometry exam, including only adults on the analysis, although children can have oligosymptomatic and misdiagnosed effusive otitis, what can be an objective of study for future research.

\section{Conclusion}

Healing quality outcomes are important for patients and physicians, since not only the esthetic impairment can be evaluated, but also the long-term results of surgical techniques in local physiology. Improving scar-related issues may also have long-term benefits in the patient's quality of life.

The osteoplastic flap surgical technique for mastoidectomy closure in cochlear implant surgery caused no intraoperative or postoperative complications, showing that it is a safe and effective surgical technique.

This study promotes the osteoplastic flap technique as a recommendation for opening and closing the mastoid cavity in ears without chronic inflammatory conditions, as it presents superior esthetic and functional results.

The osteoplastic flap technique is better than the traditional technique for maintaining a mucosa capable of performing gas exchanges, which keeps the mastoid cavity aerated in the long term, with less interference in sound absorption, especially in frequencies that concern speech.

Supplementary Information The online version contains supplementary material available at https://doi.org/10.1007/s00405-021-06907-1.

Funding For all the authors, none was declared.

\section{Declarations}

Conflict of interest This work has no conflict of interest.

\section{References}

1. Yuen HW, Chen JM (2008) Reconstructive options for skull defects following translabyrinthine surgery for vestibular schwannomas. Curr Opin Otolaryngol Head Neck Surg 16(4):318-324

2. Hongo T, Komune N, Shimamoto R, Nakagawa T (2019) The surgical anatomy of soft tissue layers in the mastoid region. Laryngoscope Investig Otolaryngol 4(3):359-364

3. Magnuson B (2003) Functions of the mastoid cell system: autoregulation of temperature and gas pressure. J Laryngol Otol 117(2):99-103

4. Eden AR, Laitman JT, Gannon PJ (1990) Mechanisms of middle ear aeration: anatomic and physiologic evidence in primates. Laryngoscope 100(1):67-75

5. Seibert JW, Danner CJ (2006) Eustachian tube function and the middle ear. Otolaryngol Clin North Am 39(6):1221-1235. https:// doi.org/10.1016/j.otc.2006.08.011

6. Stratigouleas ED, Perry BP, King SM, Syms CA 3rd (2006) Complication rate of minimally invasive cochlear implantation. Otolaryngol Head Neck Surg 135(3):383-386

7. Doyle WJ (2007) The mastoid as a functional rate-limiter of middle ear pressure change. Int J Pediatr Otorhinolaryngol 71(3):393-402

8. Doyle WJ (2017) A formal description of middle ear pressureregulation. Hear Res 354:73-85. https://doi.org/10.1016/j.heares. 2017.08.005

9. Gaihede M, Dirckx JJ, Jacobsen H, Aernouts J, Søvsø M, Tveterås K (2010) Middle ear pressure regulation-complementary active 
actions of the mastoid and the Eustachian tube. Otol Neurotol 31(4):603-611

10. Sadé J, Fuchs C (1997) Secretory otitis media in adults: II. The role of mastoid pneumatization as a prognostic factor. Ann Otol Rhinol Laryngol 106(1):37-40

11. Sadé J (1992) The correlation of middle ear aeration with mastoid pneumatisation. The mastoid as a pressure buffer. Eur Arch Otorhinolaryngol 249(6):301-304

12. Alper CM, Kitsko DJ, Swarts JD, Martin B, Yuksel S, Cullen Doyle BM, Villardo RJ, Doyle WJ (2011) Role of the mastoid in middle ear pressure regulation. Laryngoscope 121(2):404-408

13. Fearmonti RM, Bond JE, Erdmann D, Levin LS, Pizzo SV, Levinson $\mathrm{H}$ (2011) The modified patient and observer scar assessment scale: a novel approach to defining pathologic and nonpathologic scarring. Plast Reconstr Surg 127(1):242-247

14. Minoda R, Yanagihara N, Hinohira Y, Yumoto E (2002) Efficacy of mastoid cortex plasty for middle ear aeration in intact canal wall tympanoplasty for cholesteatoma. Otol Neurotol 23(4):425-430

15. Koç A, Ekinci G, Bilgili AM, Akpinar IN, Yakut H, Han T (2003) Evaluation of the mastoid air cell system by high resolution computed tomography: three-dimensional multiplanar volume rendering technique. J Laryngol Otol 117(8):595-598

16. Terzi S, Özgür A, Erdivanli ÖÇ, Coşkun ZÖ, Ogurlu M, Demirci M, Dursun E (2015) Diagnostic value of the wideband acoustic absorbance test in middle-ear effusion. J Laryngol Otol 129(11):1078-1084

17. Bento RF, Tsuji RK, Fonseca AC, Alves RD (2017) Use of an osteoplastic flap for the prevention of mastoidectomy retroauricular defects. Int Arch Otorhinolaryngol 21(2):151-155

18. Hopfenspirger MT, Levine SC, Rimell FL (2007) Infectious complications in pediatric cochlear implants. Laryngoscope 117(10):1825-1829
19. Vila PM, Ghogomu NT, Odom-John AR, Hullar TE, Hirose K (2017) Infectious complications of pediatric cochlear implants are highly influenced by otitis media. Int J Pediatr Otorhinolaryngol 97:76-82

20. Committee on Infectious Diseases, Rubin LG, Papsin B (2010) Section on otolaryngology-head and neck surgery. Policy statement-Cochlear implants in children: surgical site infections and prevention and treatment of acute otitis media and meningitis. Pediatrics. https://doi.org/10.1542/peds.2010-1427

21. Ars B, Wuyts F, Van de Heyning P, Miled I, Bogers J, Van Marck E (1997) Histomorphometric study of the normal middle ear mucosa. Preliminary results supporting the gas-exchange function in the postero-superior part of the middle ear cleft. Acta Otolaryngol 117(5):704-707

22. Kim SY, Han JJ, Oh SH, Lee JH, Suh MW, Kim MH, Park MK (2019) Differentiating among conductive hearing loss conditions with wideband tympanometry. Auris Nasus Larynx 46(1):43-49

23. Ellison JC, Gorga M, Cohn E, Fitzpatrick D, Sanford CA, Keefe DH (2012) The wideband acoustic transfer functions predict middle-ear effusion. Laryngoscope 122(4):887-894

24. Prieve BA, Feeney MP, Stenfelt S, Shahnaz N (2013) Prediction of conductive hearing loss using wideband acoustic immittance. Ear Hear 34(Suppl 1):54S-59S

25. Hunter LL, Prieve BA, Kei J, Sanford CA (2013) Pediatric applications of wideband acoustic immittance measures. Ear Hear 34(Suppl 1):36S-42S

Publisher's Note Springer Nature remains neutral with regard to jurisdictional claims in published maps and institutional affiliations.

\section{Authors and Affiliations}

\section{Paula Tardim Lopes ${ }^{1,7}\left(\right.$ D $\cdot$ Ricardo Ferreira Bento ${ }^{2,7}$. Eloisa Maria Mello Santiago Gebrim ${ }^{3,7}$. Roberto Miquelino de Oliveira Beck ${ }^{4,7}$. Renata Mota Memede Carvallo ${ }^{5,7}$. Seisse Gabriela Gandolfi Sanches ${ }^{6,7}$. Juan Carlos Cisneros Lesser ${ }^{7}$}

1 Medical-Assistant Otolaryngology Department, $\mathrm{PhD}$, University of São Paulo School of Medicine, Av Dr. Eneas de Carvalho Aguir $2556^{\circ}$. Andar sala 6167, São Paulo 05403-000, Brazil

2 Professor and Chairman of Otolaryngology Department, University of São Paulo School of Medicine, São Paulo, Brazil

3 Professor and Chairman of Radiology Department, Hospital das Clínicas, University of São Paulo, São Paulo, Brazil

4 Medical-Assistant Otolaryngology Department, PhD, University of São Paulo School of Medicine, São Paulo, Brazil
5 Associate Professor, Department of Physiotherapy, Communication and Hearing Sciences \& Disorders, and Occupational Therapy, University of São Paulo, São Paulo, Brazil

6 Audiologist PhD, Department of Physiotherapy, Communication and Hearing Sciences \& Disorders, and Occupational Therapy, University of São Paulo, São Paulo, Brazil

7 Otorhinolaryngology Department, $\mathrm{PhD}$, National Institute of Rehabilitation, Mexico City, Mexico 